\title{
Sacred Economics: Sharing in the Higa-onon Tribe of Iligan City, Philippines
}

\author{
Artchil C. Daug
}

\begin{abstract}
The Higa-onon tribe is one of the major indigenous groups in Iligan City, in Northern Mindanao in the Philippine Islands. At present, they continue to live as farmers and are trying to keep their tradition alive. In their development as a tribe, they were able to develop moral and ethical concepts that became the backbone of their culture. This study examines these concepts and, through interviews, community immersion and participant observation, argues that the Higa-onon concepts of Ginagawa, Gantangan and Batasan Adansil came as a product of the kind of farming tradition they were able to develop. Oral narratives and accounts of the tradition tribal elders called the Baylan show that there is a strong link between these concepts and how they were derived from the economic activities of the Higa-onon. Furthermore, basing from the Higa-onon experience, a change in paradigm to bring sacredness to the current prevailing capitalist paradigm may require a change in the system itself; one that is based on sacred valuations and not of the market system.
\end{abstract}

Index Terms-Higa-onon, Batasan Adansil, Gantangan, Iligan city.

\section{INTRODUCTION}

This generation, and probably the ones that will follow, is facing a crisis in meaning. Eliade saw this in our obsession with history, now merely a list of dates and events. $\mathrm{He}$ attributed this crisis to the absence of any form of connection towards what he called "the sacred" and the turning of everything into the mundane-devoid of any intrinsic meaning and value. Meaning is present only if needed or required [1]. Looking at socio-economic relations, Eisenstein called this absence of meaning "separation", which can be observed in "the human/nature split, the disintegration of community, the division of reality into material and spiritual realms" [2]. Objects and materials within the realm of human exchanges no longer mean anything, unlike for example the exchanges found in Malinowski's observation of the people of Trobriand Islands. Malinowski argued for new sets of perspectives on valuations; one that handles wealth "ritually" and as something meaningful. Human exchanges should not be treated as trivial, but as meaningful as "some of the most important acts of native life" [3]. It was also in this same spirit that Mauss suggested the evaluation of western valuation to that which reconnects people to the sacred intrinsic values of

Manuscript received July 8, 2016; revised October 21, 2016. This work was supported in part by the Faculty Development Program of the MSU-Iligan Institute of Technology as part of a scholarship received by the author.

A. C. Daug is with the Department of History of MSU-IIT. He is also with the Graduate Anthropology Program of the University of San Carlos in Cebu City, the Philippine Islands, Philippine (e-mail: artchildaug@gmail.com). things-and therefore to one another-in order not to produce a citizen that is "either too good or too individualist nor too insensitive or too realist" and who does not simply "have a keen sense of awareness of himself, but also of others, and of social reality" [4]. There is an understanding that this individualistic tendency came as a product of meaningless exchanges wherein, according to Sagoff, "market relationships displace the bonds of community, compassion, culture, and place" [5].

It is within this perspective that there is a need to look at cultures in the peripheries in order to observe societies that are not yet intoxicated by this absence of meaning, where "separation" is not yet observable. The subject of this paper is the Higa-onon tribe of Iligan City in the Philippine Islands. It aims to provide an example of human exchanges that promote economic relations that create, and not displace, the "bonds of community, compassion, culture, and place". This paper thus attempts to answer the following questions: what is the traditional farming system of the Higa-onon tribe and how did this tradition foster a community-based social relations, particularly the concepts of Ginagawa and Batasan Adansil, a set of principles that govern Higa-onon behavior in general.

\section{RESEARCH METHOD}

The current paper is a product of an ethnography that started in 2012 and is comprised of community immersion, participant observation, and formal and informal interviews. The main informants are the Baylan Kaligaun Eladio Sangcoan, who is around 67 to 68 years of age; and whenever available, his older brother Dionesio Sangcoan, who is around 70 years old. The main contact, guide and translator whenever necessary is the son of Baylan Eladio, the 33 year old Datu Kilala Lanelio Sangcoan (enthroned as tribal leader by December 2014).

Data collected from the interviews included stories, folklore, and allowable portions of their genealogy (understood as the sacred narrative of their past and the origins of their culture). The data included in this paper includes the farming tradition of the Higa-onon and the explications of the Baylan regarding the Higa-onon concepts of Ginagawa and Batasan Adansil. It is important to emphasize here that unless granted the title of Datu, a researcher is limited only to information that a Baylan (the tribal authority in culture) found allowable. The preliminary interviews in 2012 resulted to an understanding that in terms of knowledge and wisdom, which the Higa-onon only have one term Tanod, the Baylan holds almost unquestionable authority. The description of Higa-onon culture found here mostly come from Baylan Eladio and Baylan Dionesio. 
Another Baylan was supposed to be interviewed in 2013, but he referred the researcher back to Baylan Eladio (who in a moment of complaint was demanding the other Baylan to learn more because he could not do interviews forever). The data on farming tradition here came from earlier interviews, specifically those in October 2014. The interview conducted in March 2015 composes the section on Ginagawa. However, the data presented here remain subject to improvements as the hermeneutic continues with further community immersion and social interaction with the Higa-onon community.

\section{THEORETICAL FRAMEWORK}

The theoretical framework is based on the social analysis by structuralist Marxism of critical theory found in Sim and Van Loon who explained that the superstructure that is composed of "religion, politics, law, education, the arts, etc." or "everything cultural" is based or "determined by a specific economy" [6]. It is the argument of this paper that Higa-onon culture is determined by their economic activities. This is to say that the structure of Higa-onon ethics and the interaction between the self and the community found for example in Daug and Neri [7], as explained below, is deeply rooted in the tribal economy of the Higa-onon.

\section{LOCALE OF THE STUDY}

The present cultural homeland of the Higa-onon of Iligan City in the Philippines is located in Barangay Rogongon (a city in the Philippines is always divided into districts called Barangay, and a Barangay is divided into sub-districts called Sitio). It is a considerably remote area found on the hills surrounding the eastern portion of the city. The Higa-onon tribe was considered as the city's resident indigenous tribe. Though they are sporadically found in Barangay Rogongon, most of them have residences in Sitio Poblacion-the center of barangay activities in the area. Sitio Poblacion is surrounded by hills and forests in almost all direction except for the part where a national highway is being constructed.

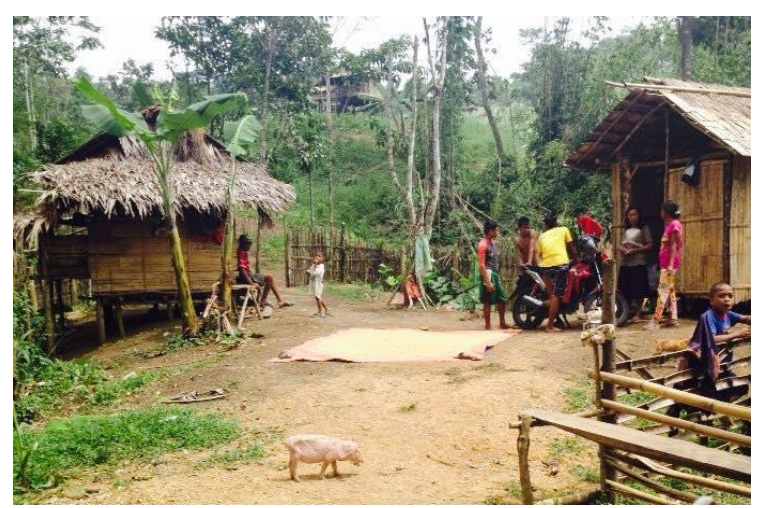

Fig. 1. Center of the Higa-onon a farming community by the Sangcoan clan in Barangay Rogongon, Iligan city.

Before and even during the Spanish Period (1565-1898), the Higa-onon were already establishing communities in the area that became Yligan and later on Iligan. Most of the names of the old Barangays in the city are Higa-onon terms: Dalipuga, Tibanga, Tambacan, etc. [8]. The Higa-onon are also based on clans, and in all the study this author conducted, informants came from the Sangcoan clan. This is because of the considerable amount of respect the other clans have for them. At present, the community crafter of the sacred Gantangan (an object which design came only to those who were instructed by their gods) belongs to their family-only one man for now though he is trying to relay the gift of making the Gantangan to a protégé of his. In this clan also belongs the only recognized convener of the Kaamulan festival in the community-ten days of cultural celebration involving the genealogy of the tribe and culminating with an enthronement of several Datu (tribal leader).

\section{HIGA-ONON CONCEPTS}

Three concepts from the study of Daug and Neri is necessary to have an idea of the Higa-onon language game. Their study offered a brief outline of Higa-onon concepts that are important in this paper.

First, though seldom mentioned, is the Kagwolong. This is the Higa-onon term almost equivalent to the western notion of "the self". It is "the understanding of the Higa-onon individual of his or her role in Higa-onon society" and his or her awareness of his or her connection with other Higa-onon [9] For a Higa-onon, the self is always attached to the community and the community's past.

Second is Ginagawa. Mentioned mostly in almost in conversation from farming to drinking, from behaving to chewing, Ginagawa is the Higa-onon concept for balance. The Higa-onon always weighs his or her actions based on the motive of keeping balance. In common conversations, it is synonymous with love and care because the presence of both can assure balance in all forms of relationships. "There is balance in nature that is required to be kept, and this balance resembles the perfection, the oneness, of the creation of the Magbabaya... Ginagawa is intrinsic in creation and as such is part of the Kagwolong of the Higa-onon existence" [9]. Ginagawa also presumes there is meaning to everything because everything is created by the Magbabaya.

Third, is the concept of Gantangan, which is materially just an object (commonly used in post-war Philippines as a standard for measuring rice sold in the local markets), but represent something so much more in Higa-onon culture. For the Higa-onon, especially "in ethical judgment, the Ginagawa becomes the concept of Gantangan (weighing or scaling), wherein the Higa-onon weighs the circumstances of his life" [9]. The Gantangan is the exercise of Ginagawa. The idea is that a Higa-onon always weigh situations in order to keep Ginagawa. This determines social relations, relations with deities, and with nature itself. This becomes more visible within the next concept.

Lastly is the concept of Batasan Adansil. Roughly synonymous to a set of ethical code, the Batasan Adansil is typically understood as "the way things should be". It is common to simply translate this as "customary laws", but such a phrase is misleading considering the complexity of the concept. The Batasan Adansil is almost completely relativistic and is usually based on the abilities of the tribal leaders to practice the keeping of Ginagawa and the exercise 
of Gantangan. "This system of weighing and keeping balance is called Batasan Adansil. The Batasan Adansil adjusts in every situation, uses the past as a guide for judgment and exercises the Gantangan to weigh things down and deliver justice. Judgments passed are recorded in memory and oral tradition; and [this recording] becomes part of the Kagwolong of the Datu in times when the Datu becomes Batasan Adansil" [9]. Note the expression "the Datu becomes Batasan Adansil" because the usage of the phrase this way is common in conversations with the Datu and the Baylan. This is not to be taken as meaning "the Datu becomes or an embodiment of the customary laws" because such an expression presumes a pre-existing set of laws. This phrase means that the Datu knows exactly what he is doing because of his experiences and the experiences of past Datu who he learned from.

This paper connects these concepts to the economic activities of the Higa-onon. By bringing together their experiences in what it means to do labor and what it means to behave, this is an attempt to provide a material base for these Higa-onon concepts.

\section{HIGA-ONON FARMING TRADITION}

Farming follows a calendar based on the stars or star formation. Only the Baylan can read the stars. These stars or star formation/position are provided names by the Baylan. The Baylan identifies the star formation, but a more accurate naming cannot be disclosed to the researcher (indeed, only the Baylan knows). Nevertheless, the following estimate equivalents to the regular Gregorian calendar were provided: Magbangal (first day of January), Magbangal and Malala (January to May), Tiyok (June to August), and Molopolo (September to December).

When the Magbangal appears, preparations begin. The Baylan and the Datu, as leaders of the community, gather the different representatives of the clans. The Baylan reveals a schedule for the cycle. The community is then instructed to prepare for planting and farming. The first part of the schedule is the pag-ihap ho palanaplanap daw mga kayo, which is a kind of forest resource inventory. The Higa-onon practices shifting cultivation and moves from site to site for farming. The inventory helps them judge the quality of the land and its readiness for cultivation. After using a piece of land, they typically leave the place alone for an estimated seven cycles in order for the land to restore its fertility and natural order, though there were times when it can reach twenty to thirty cycles depending on the state of the land. A land is judged fertile if its former state as a lasang (jungle/forest-like) is restored. A newly restored environment is called mangohod ha lubas, signifying that it is young. A more mature environment, which is always preferable, is called magulang ha lubas. The Higa-onon then decides on the site to be used, after which a ritual follows. If however a site is proclaimed as unsuitable, or that the natural conditions have not been met yet, the Higa-onon would then look for another site. Batasan Adansil in resource management is again based on the principle of balance.

Higa-onon farming regularly starts with a ritual and culminates with a ritual. This is again in keeping with the tradition of asking permission to the Magbabaya that began with the Datu Tanggungan, who was a spirit. There are five nature spirits that are called upon by the Higa-onon for permission and help: Datu Tanggungan, Daral, Maumin, Nangako and Alu-ala. These spirits are referred to as Tagayuta, spirits that dwell on the land, and it is only in calling for them that the land would be selected and prepared. Without them, no success can be expected of farming or that farms became usually infested by rats. In other cases, as in the water project in Mt. Malindawag in Naawan, a ritual is performed by the Baylan to call upon the nature spirits to permit the use of water in the land. The ritual that allows farming is called Ibabasok and it is here that the Higaonon asks a sign from the bird Limokun that it is indeed safe for the land to be used.

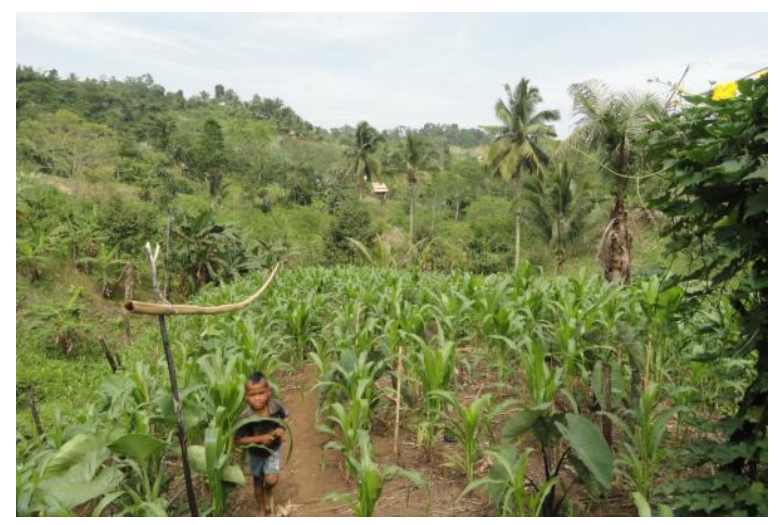

Fig. 2. A Higa-onon farm in Barangay Rogongon, Iligan city.

After the ritual, and with the land decided as fertile and safe, the Higa-onon then proceeds to clear the lasang-clearing tall grasses, cutting off trees, removing undergrowth, etc. This is usually done during Magbangal. The clearing culminates with the burning of the grasses and leaves and other organic particles that are scattered in the land. This is a community affair as the clearing provides clan members to interact with each other. Young ones were taught as the adults go by their business. There is no distinction between man and woman in terms of labor capacity. Everyone who can work, works. Men were usually in-charge of preparing the land for planting, while the women-because of their more accurate hands-are typically in charge of the actual planting of the seeds. It was mentioned in the interviews that young adult Higa-onon participate in the planting actively as this was a good source of socialization. The Higa-onon usually plant corn and rice. Harvesting happens during Malala and it is culminated with a ritual called Lagti, the ritual of thanksgiving.

It is important to note that not all clans or families are doing this simultaneously because it could be the case that the clearing may take longer in other areas while short in some areas. The first family or clan who can harvest performs the first Lagti. This is a thanksgiving for the rice and an announcement of a successful harvest and everyone is invited to share with them. Everyone who participates are provided for and were given rice. It is the responsibility of the family that underwent harvest to provide for the community as part of their tradition and whenever necessary. The Lagti includes the offering of stalks of rice, which they consider as the living representation of life. Sacred rice represents "gatubo nga 
humay", which is taken to mean "growing life". Labor or "ang hago" suggests the existence of life. Thus, the stalks of rice represents man's labor in the natural world, and represents what the natural world is to man.

Newly harvested rice is cooked but only after the first part of the ritual is performed (the Baylan offers the stalks and sacrifices a chicken which blood is sprayed on the stalks), because cooked rice is dead rice and does not represent living rice. Just like the living chickens that are to be sacrificed after the Baylan communicates to the Magbabaya, rice too should be offered in its living natural form. It becomes part of the Agsiwa (tribute to the gods). Later, the rice is cooked and then appropriated by packing them with banana leaves.

Just as the planting and harvesting, this is a community affair. Members of different clans come not merely as guests but as active participants in the preparation, the cooking, the rituals and the celebration in general. The harvest of a family is the harvest of the community. The distinction created upon the notion of modern private property does not exist here. The act of giving (sharing) is part of the entire activity and the family should not feel obligated but feel proud for having given. This too is symbolized in the second part of the ritual.

In this second part, rice packed in banana leaves are then placed in a platform, together with the cooked chicken. A nigo (winnowing basket) is also placed beside them. Inside it is living rice designed to a shape like that of a human being; this formation is called pilipig and the entire setup is called pinalipig. The idea is that human life can only come with rice, since rice is understood as "lalang sa langit" (a gift from the Magbabaya). Not only that. It also signify the connection between nature and being human, and the connection between human beings. Inasmuch as the other families can partake from the harvest of another family, they too will later carry a portion of the pilipig as a symbol of their participation. The pilipig also symbolizes Ginagawa, meaning that in the entire farming activity balance was kept and that the Higa-onon did not abuse the sanctity of nature and of themselves while performing human labor. This is Batasan Adansil. The keeping of the Batasan Adansil in the two rituals, Ibabasok and Lagti, determines the pauyaw-uyaw, roughly translated as the outcomes of the farming activity. The Higa-onon believes that farming without the necessary rituals is equated with "walay batasan", which in Higa-onon means the disrespect to the appropriate ways of dealing with nature (in Cebuano, the phrase means "lack of appropriate behavior").

The coming of the Tiyok (roughly translated as "crisis") is due to the fact that the Higa-onon typically rest themselves and the land every after harvests. They do not plant without regards to the land. During this time of limited resources as nature is made to rest, members of the community-be it member of the same clan or not-support each other. Fruit trees and bananas are common and it was said that when a Higa-onon found himself or herself hungry from a journey and it so happened that there are edible fruits around him but belonging to another family's charge, s/he can eat the fruit without permission as long as s/he will not leave a mess (doing so is interpreted as an insult). As usual, the community leaders are tasked to wisely appropriate the products of the harvest.

\section{GINAGAWA AND BATASAN ADANSIL}

The Baylan explained that the act of giving and providing during harvests is in line with the community spirit that started the planting period. This sense of connection between the members of the community is the source of the Ginagawa. For example, in the later portion of the Tiyok, the Higa-onon must prepare for the celebration in the Molopolo. The Baylan Eladio explained: "So the Datu, who is the leader of the tribe, tells the community to farm so when the months of October and November comes, we can serve during the festival. So what must they do? We farm side-by-side because there are wild animals back in the days that can destroy the farm... A hectare for me then you also have a hectare beside it, just like that, side-by-side. Until the entire area cleared, group by group. The group is united. When the time to harvest comes, those who can harvest plucks the stalks and performs the pinalipig. That is the source of Ginagawa."

Note here that this answer was a reaction to a question on giving and sharing. That it immediately moved from farming to Ginagawa is typical of any conversation with the Baylan. It is always emphasized even in any topic. The mention of Ginagawa here is connected to the sacredness of the rice and the ritual that culminates its harvest. As mentioned above, the entire affair of giving and sharing is demonstrated in the ritual itself. He added: "That is one source of the Ginagawa. In the first pinalipig, in plucking the rice stalks, we send a message to those above. That now we receive the body of the Magbabaya through the harvest. We will use it now so forgive us that we bear no ill will. So we give to the nature spirits and the others. After the pinalipig, we pack for the number of households present. We give a pindit, just a little, seven granules of rice. We give that to the households. If there are a hundred households, then we give hundred packs that announces that I already harvested. So they can now approach me for exchange. How much you exchange is equated by your own produce. The one you will harvest, you exchange with mine. When s/he harvests later, because his or her came later, s/he can repay what I gave. It is also bad to exploit (this arrangement). It is bad not to give back."

This responsibility of sharing is enforced by the Datu. This also explains why the responsibility of the Datu to the community is heavy. The act of giving is usually compensated by the feeling of pride that one was able to give. Although this is true for all capable Higa-onon, the responsibility of the Datu includes keeping members of the community satisfied. The Datu who lives this principle by example is thus described as: "That is the sign of the honorable Datu. Those who are in need, those who are hungry, those who are thirsty, those who came from faraway places can stay in his house, can sleep and can eat. Whatever the problems of the people are, they can approach him. It only means that you are a leader. You are a Datu. It is not good for a Datu to be talauna... a selfish one. You strive to be honorable. That is your honor; that is your pride, and that is what you will be known for."

That the Baylan here sounded like giving a lecture is because this interview was hoped to become a focused group discussion. But whenever the Baylan spoke, the three newly enthroned Datu who were with the researcher can only affirm what was explained. The researcher suspects that the Baylan 
used the interview to indirectly lecture the newly enthroned Datu, which included his son. He continued: "You who is considered a leader, if you want to work, and whenever you are working in the field, you will be helped by the community members who saw you as a leader and this without any compensation. But when they return home, you give them something. There were no compensations before. If you are a leader, a Datu, you will be helped. But you must also understand that the one who helped you have hungry mouths to feed in his or her family."

For the Higa-onon, the leader always gives not in a sense of a wage, but in sense of valuation. The Datu values the help and the circumstances of the helping. He later summarized this reciprocal nature of relations among members of the community as: "Just like you here; you give me something and I give you something in return. Magbabaya has nothing to do with that relationship because it is only between us. That is what is called Ginagawa. That is Ginagawa: I have mine, and you have yours; so we share."

In this instance, the conversation went towards the notion of unfairness. This concerns the valuation of the materials given and received. In the case of the Datu, unreciprocated giving is the more favorable situation. The Baylan explained: "Nothing of that sort [the feeling of unfairness]... No, no. Even if you give your carabao, or anything for that matter, nothing can make you say that it is unfair that you give and failed to receive in return."

This notion of reciprocity-of paying back in kind, or even paying forward-is considered as the right mindset; that is, Batasan Adansil. The act of sharing and receiving is determined by how much a Higa-onon knows his or her self in relation to others. The Higa-onon therefore must learn to associate with others, and this association was considered more valuable than the objects exchanged. In Batasan Adansil, the exchanged objects are themselves meanings that imply the community. He added that "friendship or acquaintance is important for the Gantangan. Socialization. You must socialize with everybody. You must be respectful to others. That is Ginagawa. You should not be choosy." This view on social relations appear to be typical in a communal setup. Farming activities within the community necessitated closer relationships between its members.

\section{DISCUSSION}

The Higa-onon farming tradition alludes to the leadership of the Datu to orchestrate farming activities, and efficiency is not necessarily measured in terms of profit. Material commodity valuation, the same kind used in the Market System, is alien to the Higa-onon before the articulation of the mode of production by capitalism. The Higa-onon values life within the context of Ginagawa and Gantangan. Nature for them is not just matter, it is the manifestation of the Magbabaya. This appears to be the intrinsic value of everything. The meaning of existence is fixed within everything. In the Higa-onon Kagwolong, there is no need to find the meaning of life in pages of books. It is in his or her actions that the Higa-onon creates (from the gifts of the Magbabaya) meaning with others. Everything therefore is
Pamalihi (sacred) and the need to balance everything (Ginagawa) found expression in the continued weighing of everything (Gantangan) based on this sacredness.

In other cultures, the Gantangan is simply a measuring equipment. In the Higa-onon culture, it is Lalang sa Langit. Rice too belongs in this category, including the mamá (a chewable combination of betel nut, lime, tobacco, and a leaf from a tropical vine). Nature too is considered sacred. The Higa-onon complains whenever they are pictured as nature worshippers, because one does not worship nature. One however needs to converse with nature.

Observe however that all these sacred elements of their culture are all related to farming. In the planting of rice, the Higa-onon typically chew the mamá because, according to them, you can last a day in the field without eating as long as you mamá. After production, distribution is done through the Gantangan. One shares their produce to other members of the community and by a sense of duty hopes that those who partake will share theirs to others until it forms a circle. In a way, as long as community members pay forward or reciprocate, sharing helps offset the differences in farming sizes and time. It helps balance things out, just like Ginagawa. Balance is a necessity. Such a worldview however is seldom observed in contemporary society, especially in a society suffering from the economics of separation.

\section{CONCLUSION}

The entire cultural superstructure of the Higa-onon is therefore structured by its base economic activities. The Baylan explains this as the natural consequence of the daily test that the Magbabaya provides for the Higa-onon. In the interest of changing the current mindset on economic relations that is dominated by capitalism, it remains to be examined whether concepts like Kagwolong, Ginagawa, or in general Batasan Adansil, is possible without necessarily structuring society in the way the Higa-onon did. Higa-onon economics depends on the sacredness of both nature and humanity. Abusing nature is not Batasan Adansil nor is treating nature as mere objects. It is because of the sacredness of nature that the Higa-onon is required to see sacredness within Kagwolong. All interactions should therefore be sacred interactions. Economic relations thus become sacred.

\section{ACKNOWLEDGMENT}

The author thanks his wife Ashera Dyan T. Neri for technical support, Datu Kilala Lanelio Sangcoan for his guidance within the Higa-onon community in Iligan City, and the members of the Sangcoan clan and those who came from the other clans for their welcome and hospitality.

\section{REFERENCES}

[1] M. Eliade, Cosmos and History: The Myth of the Eternal Return, New York: Harper \& Brothers Publishers, 1959.

[2] C. Eisenstein, Sacred Economics: Money, Gift, and Society in the Age of Transition, Online: Self Published Online Version, 2011.

[3] B. Malinowski, Argonauts of the Western Pacific: An Account of Native Enterprise and Adventure in the Archipelagoes of Melanesian, New Guinea, London: Routledge, 1922/2002, p. 404.

[4] M. Mauss, The Gift: The Form and Reason for Exchange in Archaic Societies, London: Routledge, 1950/2002, p. 89. 
[5] M. Sagoff, "Do we consume too much?" The Atlantic, pp. 80-96, 1997.

[6] S. Sim and B. V. Loon, Introducing Critical Theory, United States: Totem Books, 2001, p. 21.

[7] A. C. Daug and A. D. Neri, "The tribal philosophical thoughts of the Higa-onon of Iligan city," Mediterranean Journal of Social Sciences, vol. 4, no. 9, 2013.

[8] M. J. Almario, "Ethnohistory of Iligan city through its old place names interpreted based on the Higa-onon context" MIH special project, Dept of History, MSU-Iligan Institute of Technology, Iligan, Philippines, 2013.

[9] A. C. Daug, and A. D. Neri, "op cit," p. 78.

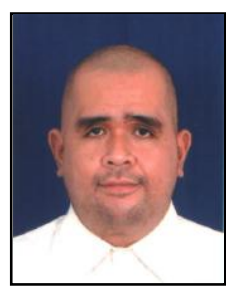

Artchil C. Daug was born in Iligan on 21 December 1980. He finished his bachelor's degree in 2004 and his master's teach degree in history in 2006 in the Iligan Institute of Technology campus of the Mindanao State University.

He joined the Faculty of the College of Arts and Social Sciences of MSU-IIT in 2004. He is an assistant professor who specializes on philosophy of history. Under the school's scholarship program for its faculty members, he is currently a student of the graduate anthropology program of the University of San Carlos in Cebu City, Philippines. 